\title{
A DYNAMIC SYSTEMS APPROACH TO WAIT TIME IN THE SECOND LANGUAGE CLASSROOM
}

\section{ABSTRACT}

This study discusses how wait time - the silent pause after a teacher elicits a student response - alters classroom discourse. Previous wait time research suggests overall positive changes in both teacher and student discourse where wait time is over 1 second. However, such studies are primarily structuralist in nature and tend to reduce the intricacy of classroom behavior to distinct variables, which can be easily altered to achieve a desired result. The data presented here comes from a series of structured observations of a UK university postgraduate L2 classroom. The findings were as follows: 1) Wait time played an intricate role in determining classroom discourse patterns and heavily favored an IRF turn-taking sequence; 2) Studentinitiated discourse was low in all observations and favored higher proficiency students; 3) The length of individual student-initiated turns appears to have been more important than the overall number of student-initiated turns in determining the quality of classroom discourse and was not directly related to changes in wait time length; 4) Extended wait time (over 2 seconds in length) temporarily shifted discourse out of an IRF pattern and into a new, more student-driven phase. While previously thought of as only a pedagogical tool to increase student speech, wait time is shown to be a phenomenon which develops and changes with the composite forces that affect other aspects of classroom discourse.

\section{Key Words}

wait time; pauses; silence; classroom discourse; elicitation; turn taking 


\section{INTRODUCTION}

\subsection{Introducing Wait Time}

Recently, educational researchers have begun to extensively study silences and pauses in the language classroom to determine their significance within classroom discourse and to improve teacher/student perceptions of these gaps in spoken discourse (Harumi, 2011; King, 2013; Nakane, 2007, Yashima, Ikeda and Nakahira, 2015). An intimately related, yet understudied area in contemporary discourse analysis is wait time. This study defines wait time as the duration between a teacher elicitation and student response or second teacher utterance. Interest in wait time increased after seminal publications by the science classroom researcher Mary Budd Rowe in 1969 and 1974, and her investigations prompted a number of subsequent studies on wait time exploring wait time's potential uses in the classroom in the 1970s and 1980s. Almost all such research argues "the quality of discourse can be markedly improved" by manipulating these particular pauses (Rowe, 1986, p. 48). Notably, researchers across disciplines found an average wait time of one second in L1 classrooms and just over two seconds in language classrooms (Rowe, 1974a,b; Shrum, 1984, 1985). Some researchers have found wait time to be a conscious product of discomfort with classroom silence, yet for others it is simply an unconscious and unnoticed pausing behavior after eliciting a response (Honea, 1982; Swift and Gooding, 1983). Despite extensive research on the subject and its seemingly positive effects on classroom discourse, wait time research fell out of favor in the late 1980s, and there has been a notable absence of research since. Educational research has since preferred the investigation of classroom processes and interaction, rather than the product-oriented approaches so heavily favored in the 1970s and 1980s (de Bot, Lowie and Verspoor, 2007). Currently, few studies exist concerning wait time in language classrooms, and there are no recent studies on the effects of 
wait time in L2 university classrooms. Most contemporary research referentially mentions wait time within larger classroom discourse processes, noting that its manipulation is an important pedagogical technique, but at times overlooking contextual classroom differences that may influence the various effects (both positive and negative) of lengthened teacher pauses (Ingram and Elliott, 2014; Kirton, Hallam, Peffers, Robertson, and Gordon, 2007). This study examines how wait time functions within the complex dynamic system of classroom discourse and how its variation is related to various occurrences of speech found therein. If wait time is related to improved classroom discourse, it seems that teachers would benefit students by making a conscious effort to lengthen these pauses.

\subsection{An overview of previous wait time research}

Despite varying definitions of quality classroom discourse, most scholars promote extended wait time as crucial in increasing student-guided discourse, arguing that extension allows more time for cognitive processing and thereby more complex speech (Honea, 1982; Rowe, 1974b; Swift and Gooding, 1983; Tobin, 1986). Characteristics of such discourse include high student-to-student interaction, student questions, and a more relaxed and congenial atmosphere (Honea, 1982; Stahl, 1994). Many researchers note wait time's relationship to elicitations, linking high cognitive level questions to extended wait time (Boeck and Hillenmeyer, 1973; Tobin, 1986; White and Lightbown, 1984). They argue that this transformed classroom environment not only improves student discourse, but also fosters student confidence and achievement, which have a cyclical effect on discourse (Riley, 1986; Tobin, 1986). The only exception is Gambrell (1983), finding shorter wait time after higher cognitive level questions in L1 third grade (ages 7-8) classrooms in the U.S. She proposes that shorter wait times after these 
questions indicate the teacher's assumption that students will be unable to respond. Wait time research in a second language context is limited to Shrum's work, notably the only conclusive set of wait time studies in second language classrooms $(1984,1985)$. She finds that wait times in French and Spanish L2 classrooms are longer than the one second average found in L1 classrooms, with teacher wait time averaging 1.9 seconds (1985). With student level as an independent variable, Shrum (1984) finds longer wait time after questions to high and low-level students, positing that longer wait time indicates language teachers' awareness of their students' processing needs. However, many of these studies reduce classroom behavior, especially wait time, to a distinct variable which can be easily manipulated to achieve a desired result. In this way, wait time research can be limiting due to its inapplicability across classroom contexts, and in fact, many researchers have disputed the efficacy of extended wait time in all classrooms, as holistic student achievement is not easily quantifiable. Some scholars have found feelings of frustration and confusion among students during longer periods of silence (Duell, Lynch, Ellsworth, and Moore, 1992; Duell, 1994; Author, 2013; Kirton et al., 2007; Tincani and Crozier, 2008). Contemporary researchers (e.g., Ingram and Elliott, 2014; Kirton et al., 2007; Sun, 2012; Tincani and Crozier, 2008) have taken a more process-oriented approach to wait time, with mixed results. Ingram and Elliott (2014) observed how wait time can affect classroom turntaking behavior, finding that wait time is built into and enables classroom talk with a heavy reliance on IRF (Initiate, Response, Feedback) discourse (Sinclair and Coulthard, 1975). They also found that extended wait time often precluded student self-selection because it entails teacher control over pauses and student selection, which can hinder naturally flowing conversation. Clearly then, wait time and classroom discourse have a complex relationship which requires an appropriate conceptual framework through which we can view this phenomenon. 


\subsection{Dynamic Systems Theory (DST) and attractor states in classroom discourse}

Recently, an increasing number of applied linguistics researchers (e.g., Ellis and LarsenFreeman, 2009; Verspoor, Lowie, and Van Dijk, 2008; Waninge, Dörnyei, and de Bot, 2014) have recognized DST as a theoretical framework for educational research. DST-informed approaches maintain that the behavior of organic systems is not a result of causal relationships between static components, but rather of dynamic interaction between system agents (LarsenFreeman, 1997). Consequently, the system's behavior cannot be easily predicted, as altering one component may result in large, small, or no changes in the system. A DST framework accounts for the constant flux and evolution inherent in real classroom environments and for the complexity in human interaction and behavior. The approach has recently provided a useful lens through which researchers can view the silences of language learners and better understand the self as a temporal system of relational networks (see King, 2013; Mercer, 2014, 2015). Current complexity research also shows in what ways phenomena can be both cognitively and socially affective to classroom systems, such as how fossilization in language acquisition acts as an attractor state, maintained by particular aspects of the classroom and student's sociolinguistic behavior (de Bot et al., 2007; Ellis and Larsen-Freeman, 2006).

The notion of complexity helps conceptualize classroom discourse as a dynamic system, responding to feedback within and outside of the classroom environment. Changing a feature of the system, or control parameter in DST terminology, may cause the system to move into a state that dissuades student/teacher discourse, without a direct causal relationship. Thus, establishing wait time as a control parameter could show a complex relationship with other features of classroom talk and patterns of discourse. In dynamic systems, changes in a parameter can affect other forces which push the system into an attractor state, i.e., a period of relative stability within 
the system. This concept is central to our study, as attractor states are by definition difficult to overcome and can become problematic if the attractor state does not foster a communicative classroom environment.

Changes in wait time caused by other emergent behavior could theoretically shift the system into a beneficial state for student communication, depending on the initial attractor state of the classroom discourse system. Consideration of these issues led to the following research questions which seek to better understand wait time's complex relationship to classroom discourse:

RQ1. How does wait time affect the quantity and quality of student discourse?

RQ2. Does the type of elicitation affect the length of wait time?

RQ3. What do the dynamic variations in teacher wait time and student speech show us about their relationship to each other and other features of classroom discourse such as pauses, student-initiated turns, and so on?

\section{METHOD}

The investigation draws on analysis of nine hours of classroom interaction. To ensure an in-depth study of participants and because there is little wait time research observing how student discourse develops within a classroom over time, a single UK postgraduate language class was observed on multiple occasions. Each of the six observations lasted for one hour and 30 minutes, and participants were not informed of the research topic to ensure minimal behavioral changes in response to observation (Dörnyei, 2007). Observations were done over the course of six weeks, making the interval between each observation one week. Audio recordings and field notes were taken throughout each observation period. 


\subsection{Wait time and student response length}

Wait time and utterances were measured using a digital stopwatch and rounded to a tenth of a second (Rowe, 1974a,b; Tobin, 1986). A two-tailed Pearson test was performed using wait time and student response length as variables, as most research proposes a strong relationship between the two. Additionally, moving min-max graphs of wait time and student response length were created for all observations over a ten-minute time scale to help visualize moment-tomoment variability between the two (for more on moment-to-moment approaches, see MacIntyre and Legatto, 2011). These graphs are helpful in showing a system's developmental variation beside the raw data, where the min and max data are presented as bandwidths of values, which themselves can show variation over time (Verspoor, de Bot, and Lowie, 2011). On these types of graphs, high variability corresponds with wide bandwidth. Min-max graphs can also detect temporary moves in and out of the attractor state, as there is generally thought to be high variability, i.e, a wider bandwidth, around these shifts in dynamic systems (van Geert and van Dijk, 2002).

In order better illustrate the complexity of factors which determine utterance length following a period of wait time, discourse analysis was performed on individual extracts of classroom interaction. Complexity theory and discourse analysis are complementary approaches, as discourse analysis offers, "careful description of the micro-level face-to-face talk... and provides a starting point for assembling a complexity toolkit for discourse," (Larsen-Freeman and Cameron, 2008, p. 183). This analysis focused on changes in the control parameter (wait time), student-initiated discourse, and the following coded classroom variables: length of student utterances, types of teacher questions, IRF sequences, and filled and unfilled pauses. The number 
of student-initiated questions and student-initiated turns were also calculated using this coding system.

\subsection{Teacher elicitations}

Teacher questions were coded by three categories: knowledge, comprehension, and application questions, using an adaptation of Bloom's seminal Taxonomy of the Cognitive Domain (1956). Bloom's taxonomy is the most widely used and recognizable questioning taxonomy in education, and the categories reflect cognitive skills that most researchers look for in student discourse analysis (Vogler, 2005). The lowest cognitive questions are knowledge questions, which require simple recall of facts, followed by comprehension questions to which students respond with an explanation of a concept or idea in their own words. Application questions require students to solve a problem by applying pre-existing facts or ideas. Coding categories were made after pre-coding the transcripts and finding few high-level cognitive questions. Bloom's taxonomy additionally fits the needs of this research due to the teacher's preference for display questions (see Long and Sato, 1983), as variation in the types of questions was necessary in order to observe differences in post-elicitation wait time length.

\subsection{IRF sequence}

Researchers hold conflicting views on the use of IRF in the classroom, but generally agree that overuse of IRF sequence can lead to a classroom with fewer opportunities for studentled discourse (Seedhouse, 2004; van Lier, 2004). IRF remains arguably the most prevalent discourse structure in the language classroom, and Cameron and Larsen-Freeman (2007) note that through adaptation to common aspects of the language classroom, IRF has become an 
attractor state in classroom discourse (p. 11). These aspects include the nature of questions asked (i.e., referential or display questioning) and the classroom hierarchy which holds instructors as the gate-keepers to knowledge and the moderators for discussions (Hale, 2011; Waring, 2009). Additionally, classroom discourse is thought to easily adapt to IRF because it is the most economical means of realizing the institutional goals of classroom interaction, i.e., producing and interpreting language (Seedhouse, 2015). The most recent wait time research points to a more complex relationship between wait time and IRF than previously understood (Ingram and Elliott, 2014).

\subsection{Filled and unfilled pauses}

Filled pauses, such as $e r, u m$, and $u h$ occur at transitions in discourse and are used for multivariate purposes in conversation, including signaling a topic change, continuing a turn, or hesitating during cognitive processing (Flowerdew and Tauroza, 1995; Watanabe, Hirose, Den, and Minematsu, 2008). Unfilled pauses are silent and have equally varied uses, including ending a speaking turn and hesitating before an utterance or turn. Both types of pauses were counted and analyzed throughout each transcript in all classroom discourse, including but not limited to teacher questions and student responses. These pauses were chosen as classroom discourse variables due to their prevalence in L2 student speech (Riggenbach, 1991; Rossiter, 2009) and because there are no current studies on the relationship between wait time and other classroom pauses. 


\subsection{Participants and context}

Thirteen students were observed, and although one student was absent from one observation, the other students were present in all observations. The class consisted of eight women and five men, with ages ranging from early twenties to late forties. Most students shared Arabic as their native language, and only one student was an L1 Chinese speaker. Additionally, most students were continuing to a postgraduate degree in fields in either business or economics. The students were observed in an advanced speaking and listening class, as a large amount of oral classroom discourse was required for analysis and because the advanced level of the students entailed that student speech would be more complex. The postgraduate student context was chosen due to the dearth of wait time research on university level students, particularly nonnative English speakers. The class took place twice a week, one hour and a half per class, for a total of three hours of class time per week. Field notes of the classroom environment, teacher/student relationship, etc. were taken during the observation, while occurrences of classroom variables were counted after each session, using the audio recording taken during the observation. All names provided in extracts are pseudonyms.

\section{RESULTS}

Quantitative analysis focused on the relationship between wait time and student response length, where $n$ represents the number of wait time and corresponding response samples in the data set. Correlational analysis in Table 1 shows that on a Pearson two-tailed test, student response length positively correlated with wait time length $(p<.01)$, with significance $(\alpha)$ at $<.01$. Table 1 also displays $\mathrm{r}^{2}$ value, indicating a $16 \%$ variance between wait time and student response length. Considering the many classroom and affective variables that could contribute to 
variation in student response length (motivation, interest in topic, proficiency, etc.), covariation between response length and a single variable (wait time) in $16 \%$ of the data suggests an interesting dynamic. Figure 1 shows a modest positive correlation at $r=.42$. Most of the points cluster between one to three seconds, which is to be expected with average classroom wait time between 1 and 2 seconds in previous literature. However, both the numerous outliers and the inherent complexity in classroom interaction underscore the need to analyze the data qualitatively. Further analysis shows how variances are related to other variables of classroom interaction, which are not evident from a wholly numerical perspective.

Insert Table 1 here

Insert Figure 1 here

Discourse analysis of the transcripts showed an intricate relationship between longer wait time and student response length and how it is able to affect students' discourse.

\section{Extract 1: Observation 3}

46 Teacher $\quad$ They have gone bankrupt. (4.3)

47 Karim

48 Teacher

49 Fatima

50 Ibrahim

51 Fatima

52 Ibrahim

53

54 Teacher

55

56 Fatima
What does mean bankrupt? $\{.8\}$

Ah, what does it mean, Fatima? (3.6)

Ehh like um there are no profits in these shops $\{6.2\}$

No money $\{.4\}$

[no money they're done $\{1.1\}$

They can't pay the loan that it that its that they got

from the for example banks of government $\{8.9\}$

Yep um you can also say they have gone (2.0) out of business. And why? (2.3)

Maybe because they're comp-uh another a 
57 Teacher

58 Fatima

59 Teacher

60 Amir

61 Fatima

62 Teacher competition store $\{3.3\}$

Mmhmm

O:o-nline uh shops $\{2.5\}$

$[\mathrm{Mmhmm}$ yep

They didn't have a smart business woman $\{3.5\}$

I'm a business

[Yeah business woman

Note. In all subsequent transcript extracts, wait time lengths are in parentheses, ( ), while student response lengths are in brackets, \{\} .

After a 3.6 second wait time in line 48, Fatima responds with a complete sentence of 6.2 seconds, longer than the average student response. The system self-organizes into a new studentguided pattern in lines 49-53, as the extended wait time and Fatima's lengthy response gives Ibrahim time to join the discussion with a long response in lines 52-3. This extract highlights many discourse phenomena that can potentially benefit from extended wait time, from longer student utterances, to more student-initiated speech. The following extract contrastively shows how short wait time and student discourse regularly functioned within this classroom discourse system.

Extract 2: Observation 6

32 Teacher $\quad$ Yep it was a survey. What did the people in the survey, the

33

34 Ibrahim

35 Teacher

36 Ibrahim

37

38 Teacher

39 Amir

40 Ibrahim participants, what did they have to do? (1.2)

To taste the coffee $\{.6\}$

Yeah mmhmm. How? (1.2)

[xxx] drank it? $\{.4\}$

[Students laughing]

They drank it? Yeah? Could they see or not? (.5)

No, blind. $\{.7\}$

Oh yeah. $\{.5\}$

The student responses in this extract are all less than one second and follow questions with an average wait time less than the holistic average across the data (1.6 seconds). However, simply 
correlating shortened wait time with shorter student responses would be misleading, as in both extracts wait time is interconnected with other variables, most notably the type of teacher elicitation.

\subsection{Teacher elicitations}

Analysis of teacher elicitations showed interconnectedness between wait time and student response length in knowledge and comprehension questions (see previous discussion of question coding classifications).

Insert Table $\mathbf{2}$ here

Insert Table 3 here

Insert Table 4 here 
The lower-cognitive level knowledge questions were overall followed by a shorter wait time and student response length than the comprehension questions, which had, on average, a longer wait time and student response length. The following extracts illustrate this phenomenon.

Extract 3: Observation 3

48 Teacher $\quad$ Ah what does it mean Fatima? (3.6)

49 Fatima Ehh like um there are no profits in these shops $\{6.2\}$

50 Ibrahim No money $\{.4\}$

51 Fatima [no money they're down $\{1.1\}$

52 Ibrahim They can't pay the loan that it that its that they got from the for

53 example banks or government $\{8.9\}$

Extract 4: Observation 6

38 Teacher They drank it? Yeah? Could they see or not? (.5) [Knowledge] 39 Amir No, blind $\{.7\}$

40 Ibrahim Oh yeah. $\{.5\}$

The comprehension question in Extract 3 requires a longer response than the knowledge question in Extract 4. In the data, wait time often correlated with question type, connecting the variability of wait time to the type of teacher elicitation. This pattern continues in Observation 2, which contains nine application questions, averaging a 2.3 second wait time and with an average student response length of 4.4 seconds. Consequently, we expected application questions to correlate with longer than average wait time, but this relationship does not occur. These results may be skewed due to the low ratio of application questions to comprehension and knowledge questions. Additionally, the students who answered the most application questions were the two most proficient students in the class, who were perhaps more able to answer these difficult questions at length. Interest and familiarity with the topic also appeared to influence response length. Most of the students studied business or economics, thus responded more frequently and 
more in-depth in Observation 3, in which they mainly discussed features of successful business models. The actors in a system contribute their own parameters and variables, such as proficiency level, to the larger system. Social systems are "interactive and open... systems... [that] depend upon a mix of negative and positive (amplifying) feedback that...comprise the system in the light of environmental contexts" (Horn, 2008, p. 135). As such, information gained from observing social systems cannot be interpreted separately from context, as it provides a deeper understanding of data that, at first glance, appears to be anomalous.

\subsection{Student-initiated questions and turns}

Most of the observed class-time was comprised of review sessions for an upcoming exam, characterized primarily by brief question-and-answer segments. This context may explain the preference of the system toward IRF, which, in this classroom, regularly lessened the opportunity for student-initiated speech. Where student-initiated speech did occur, it was mostly in the form of one or two words answers to a low-level question.

\section{Extract 5: Observation 1}

13 Teacher

14 Karim

15 Fatima

16 Teacher

17 Karim

18 Hakim

19 Karim

20 Hakim

21

22 Hakim

23 Karim
I wrote? (.4)

I wrote keywords $\{1.3\}$

[words $\{.3\}$

Just? Where does the just come? (.5)

I: - onl- I wrote keywords el- only I:-I just $\{4.0\}$

[I just $\{.2\}$

Or I can use $\{.3\}$

$=$ I just wrote $\{.9\}$

[several students trying to correct]

Just wrote a brief description $\{1.1\}$

[only only $\{.6\}$
I

$\mathrm{R}$

$\mathrm{R}$

$\mathrm{F} / \mathrm{I}$

I

$\mathrm{R}$

R

R

R

R

R

Note. In all subsequent transcript extracts, I= Initiate sequence, $\mathrm{R}=$ Response sequence, $\mathrm{F}=$ Feedback sequence 
While this extract contains a high number of student-initiated turns, three are short interruptions that respond to low cognitive level questions. Comparatively, Extract 1 contains one studentinitiated turn, but it is over eight seconds long, indicating that other features are at play in determining student response length. In Extract 1, Ibrahim initiates a response after Farrah's lengthy answer, giving him time to formulate an appropriate response. The students interpret Hakim's pausing and repetition as a sign that he needs help, so while many students initiate speech in Extract 5, the responses are short interruptions which are meant to quickly correct, rather than collaborate with the speaker. Notably, the knowledge question in Extract 1 is a higher cognitive level than the question in the above extract, again showing a relationship between student-response length to type of question, rather than a direct relationship to wait time. So, while the number of student-initiated questions may be higher in Extract 5, the length and quality of these utterances is lower than those found in Extract 1, indicating that higher numbers of a certain student-driven feature may not always achieve a communicative classroom environment.

\subsection{Wait time and the attractor state}

The system's behavior reveals wait time's complex relationship with classroom discourse beyond teacher questions and student responses. The fairly rigid discourse structure, high ratio of teacher to student questions, and $65 \%$ of turns containing IRF sequences suggest the presence of an IRF attractor state. Wait time helps maintain the "global order" (Thelen and Smith, 1994, p. 217) of the discourse system, which can sometimes discourage student-initiated speech. Themin max graphs of Observation 2 show noticeable dips in wait time and student response length around point 9 on both graphs. 


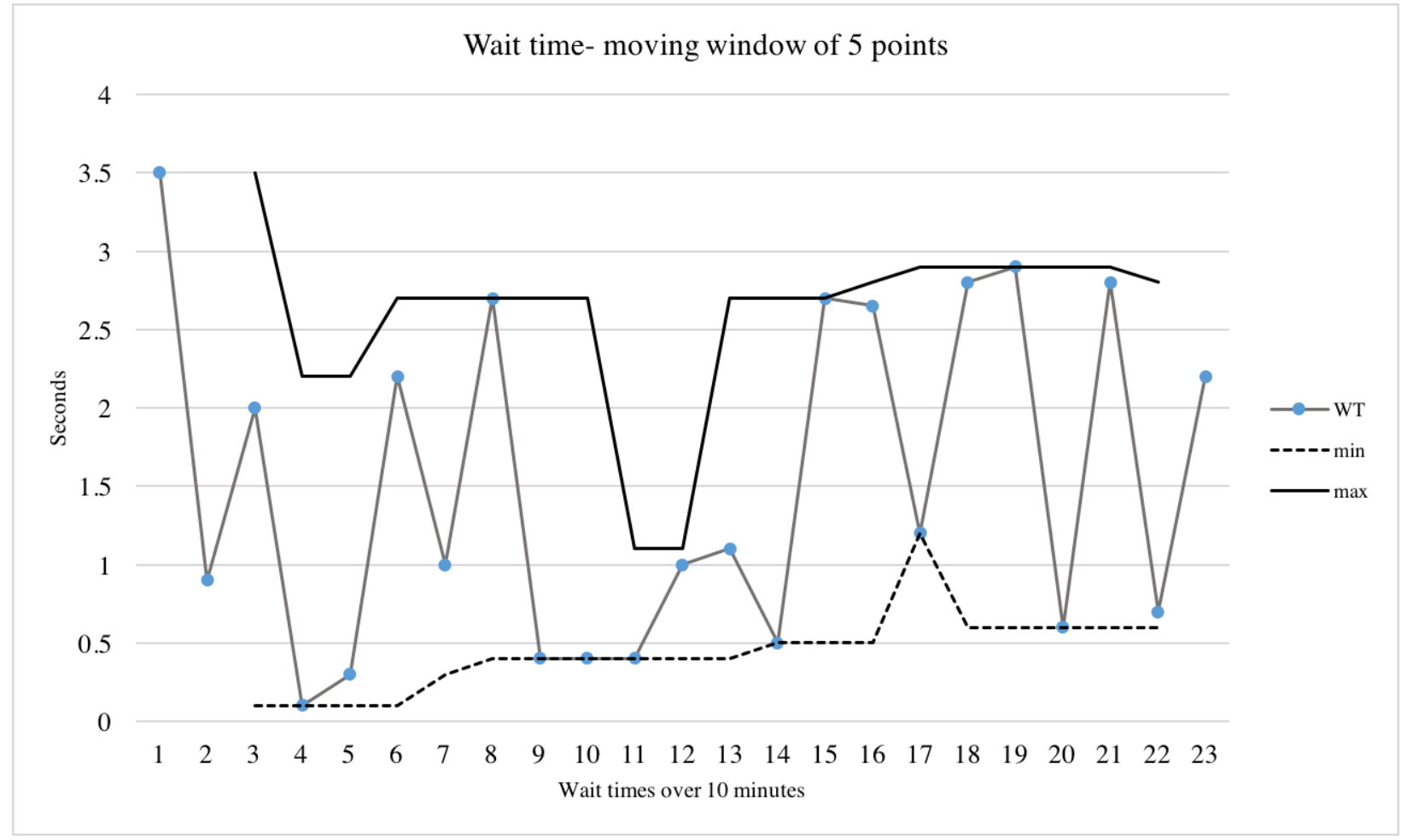

Fig 2. Observation 2 wait time length, over a 10-minute timescale

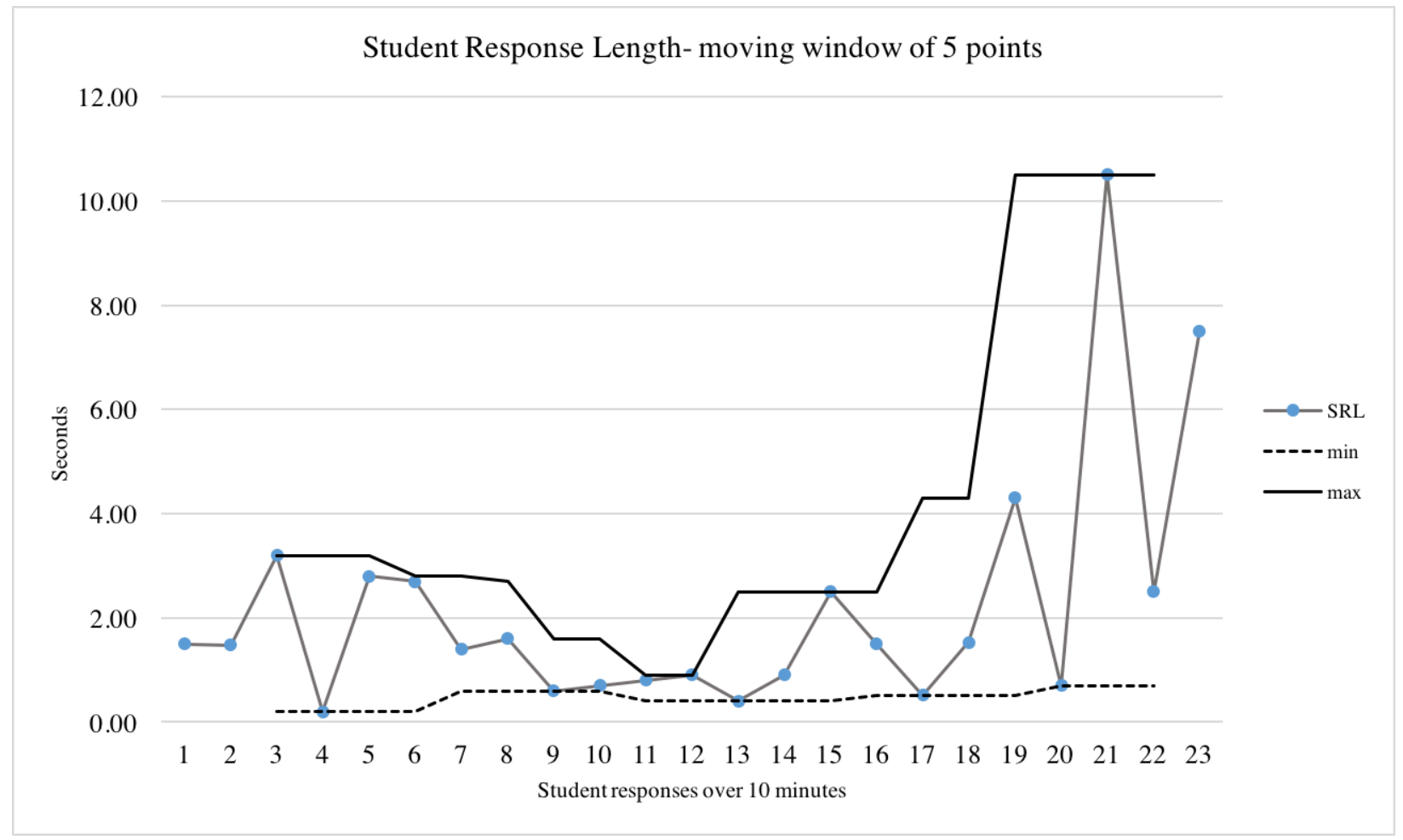

Fig. 3 Observation 2 student response length, over a 10-minute timescale 
This dip corresponds to the extract below in which the system adheres closely to the IRF attractor state:

Extract 5: Observation 2:

58 Teacher Okay. Comfortable is like this chair is quite comfortable. I

59

A car can be comfortable.

60

61 Ahmed

What else can be comfortable? (.4)

62 Teacher

Music \{.6\}

$\mathrm{R}$

Can music be comfortable? (.4)

I

63 Ahmed

Yes $\{.7\}$

$\mathrm{R}$

64

[students talking]

65 Teacher

okay. so it can be rel- (.4)

F/I

66 Ahmed

Relax $\{.8\}$

67 Teacher

It can be relax? (1.0)

$\mathrm{R}$

68 Abdullah

Yeah $\{.9\}$

$\mathrm{F}$

69 Teacher

What kind of word is this? What word form? (1.1)

$\mathrm{R}$

70

[Students saying noun, verb simultaneously]

71 Kovan

72 Teacher

noun $\{.4\}$

It's a verb isn't it, yep. So this is a verb.

If something makes you relaxed, it is? $\{.5\}$

73

74 Ali

75 Tagrid

Relaxation (.9)

[Relaxation

I

$\mathrm{R}$

$\mathrm{F}$

I

$\mathrm{R}$

$\mathrm{R}$

Longer wait time often correlated with shifts in the system, which promoted student-guided speech. Phase shifts occurred when extended wait time paired with other phenomena helped move the classroom discourse into a non-IRF sequence that encouraged student-driven discourse. The graphs show a large bandwidth between the min and max values where the system shifts into and out of IRF, showing the high variability and instability of the system around these phase shifts. Extract 6 corresponds to point 19 on the graph, beginning with a 2.9 second wait time and 4.3 second student response.

Extract 6: Observation 2

135 Teacher

So, can you answer your questions? (1.7) 
137 Tahira

138

139 Teacher

140 Tahria

$141 \mathrm{Imad}$

142

143 Karim

144 Teacher

145 Ibrahim

146

147

148 Amir

149 Teacher

150 Ibrahim

151 Teacher

152

153 Ibrahim

154

155 Teacher
The purpose uh is uh to be famous? $\{4.3\}$

$\mathrm{R}$

[students laughing]

You mean the artist (.6)

Yeah the artist. $\{.7\}$

[if this is uh accommodation

for students and he describe

the type of like $\{5.0\}$

[I like it accommodation

of students yeah $\{2.6\}$

Ibrahim, what do you think? (2.8)

$\mathrm{R}$

I

I think eh I have seen in some s-s-sometimes when when

the when the companies produce films like this they use

beds like this [laughing] $\{10.5\}$

$\mathrm{R}$

For what? $\{.5\}$

[okay $\{.7\}$

For what I don't know. I just imagine $\{2.5\}$

Okay so what does it mean, what do

you think it means as a piece of art work? $\{2.2\}$

It's not uh it-it looks in films it's real-reality

but it's not (1.0) when they record the audience $\{7.5\}$

Good.

$\mathrm{R}$

I

$\mathrm{F}$

$\mathrm{R}$

I

$\mathrm{R}$

$\mathrm{F}$

While the graphs show a definite change in the system, they only show part of the picture, as the graphs represent discrete pairs of wait time and corresponding student response lengths. Looking at the transcripts, we see how the system changes in more detail, namely, how the system briefly self-organizes into a new student-driven emergent pattern. The strength of this pattern is shown in the below extract in lines 148-149 when a student responds to Ibrahim, and the teacher interrupts the response, shifting the system back to the IRF sequence. This behavior is what we would expect from system transitions, as they "allow the system to explore new and more adaptive configurations," and are thus less stable (van Geert and van Dijk, 2002, 342). The long wait time after the application question in line 135 gives Tahira adequate time to form a response. The system shifts out of the IRF state into a student-guided discourse until line 144. Here, the elicitation allows the teacher to select a student who had previously been unresponsive 
to help him to share his opinion. The teacher's question helps shift the system back toward the IRF attractor state, initiating a downward effect on the sequence of subsequent classroom discourse. After a 2.8 second pause in line 144, Ibrahim responds at length, and Amir asks a question, which the teacher cuts short in line 149 in order to maintain Ibrahim's speakership. This is seen again in the teacher's repeated question to Ibrahim and subsequent long wait time in line 151. When the instructor helps create an environment in which Ibrahim does not need to compete, he interprets her cues (directed question, long wait time, cutting Amir short) and acts on them. When interacting with similar phenomenon, extended wait time regularly helped students respond at length, which allowed the discourse system to temporarily enter a studentdriven discourse.

Phase shifts can also push the system back toward the attractor state when wait time is shorter than average, often ensuring a short response that can be easily incorporated into IRF. In Extract 5, the four student-led turns are short, direct responses to the teacher's initial question which require little feedback and complete the current IRF sequence. There, emergent discourse is only incorporated into the system insofar as it adapts to the attractor state, thereby maintaining the system's low variability.

\subsection{Pauses}

In the data, filled and unfilled pauses mainly serve the following functions: filled pauses continue a turn or transition topics, and unfilled pauses give the speaker more time to complete their utterance. In the first three observations, the ratio of teacher filled pauses to student filled pauses was lower than in Observations 4, 5 and 6, in which there were few student filled pauses in general. Observation 4 holds the lowest wait time and shortest average student response, which seems to suggest that fewer student pauses in the sample relates to a more teacher-centric 
environment. The context of Observation 4 also seems to imply this relationship, as the lesson was mainly vocabulary review, in which the teacher would call out a word and students would respond with a short definition. Most of the observation followed a discourse pattern similar to the following extract.

\section{Extract 7: Observation 4}

22 Teacher

23

24

25 Fara

26 Teacher

27

28

29

30 Amir

31 Students

32 Teacher
Okay great. $\{.2\}$ Um I can't know if you've translated the word I correctly. I don't know if I can trust your dictionaries, which are English/Arabic or English/Chinese.

Uh huh $\{.4\}$

$\mathrm{R}$ That's the only two languages, isn't it? (1.2) Um so I don't know if you've understood the word, actually. It's not very $R$ useful for me checking, yeah? Okay. Cool awesome so. (1.8) Um we talked about bias. Compiled? If you compile something? I Mix mix two things together. $\{1.0\}$ [mix, collect $\mathrm{R}$ Yep
$\mathrm{R}$ $\mathrm{F}$

In lines 22 and 29 filled pauses appear around transitions from the feedback to the initiate sequence, which seems to help transition to a new IRF sequence. Here, the instructor's "um" following short wait times in lines 22 and 29 cue the students of a topic shift. It also reveals some interesting pragmatism by the instructor. Fieldnotes reveal that when she suggests students should not to rely on their native-language dictionaries, the instructor appears to be "uncomfortable", nodding frequently in an uneasy manner. She seems wary of offending her students in this interaction by implying that they do not completely understand their translations, so short wait time around these filled pauses allows her to quickly enter into and exit from the segue. For example, while she asks two questions in lines 26 and 28, she quickly follows both with "um", suggesting to the students that little feedback is necessary for the exchange. They 
seem to pick up on this, as the only response is a brief confirmation by Fara in line 25. Paired with the short wait time, teacher filled pauses here seem to facilitate fairly rapid IRF exchanges.

Wait time is interrelated to many other aspects of this discourse system. When wait time extends beyond the mean, usually co-occurring with higher cognitive level questions, the system can exhibit variability and enter a non-IRF pattern of interaction, which gives rise to certain discourse phenomena, like lengthier student responses. However, when low cognitive level questions abound, short wait time can enable IRF sequences, constraining discourse to the attractor state and only temporarily allowing moves outside of it. In short, the system softassembles (Thelen and Smith, 1994) toward this attractor state, and at times phenomena emerge to further help organize control IRF sequence.

\section{DISCUSSION}

In part, we observed similar findings to past wait time research. However, the only directly comparable studies of wait time in L2 classroom environments are those of Shrum (1984; 1985). The average across our six observations was 1.6 seconds, and although shorter than Shrum's 1.9-second average $(1984 ; 1985)$, this result is longer than Rowe's one-second average for L1 teachers $(1969 ; 1974 a, b)$. Shrum suggests that a longer wait time indicates L2 teachers' awareness of students' cognitive processing needs, and while providing no quantitative data for such a claim, other studies offer evidence that teachers can consciously control pauses in the classroom (Ingram and Elliott, 2014; Riley, 1986).

\subsection{Student utterance lengths and teacher elicitations}


Holistically, our results indicate that longer wait time can be indirectly associated with longer student responses, corresponding with previous research which correlates wait time to longer student utterances (Ingram and Elliott, 2014; Rowe, 1974a,b; Swift and Gooding, 1983; Tobin, 1986). In the current research and in all previous wait time studies, longer student utterances appear to be more attributable to an extended allotment of time for cognitive processing and are characteristic of an improved classroom discourse (Tobin 1986). Like Ingram and Elliott (2014), we found that extended wait time can enable longer student utterances within IRF-driven classroom discourse, but that it may impede student-selected speech. However, this phenomenon can be used to an instructor's advantage, when s/he wants to encourage a response from a particular student. While some teachers may be hesitant to adopt what seems like unnatural paralinguistic behavior, longer wait time within a controlled IRF discourse could give some students the space they require to speak up.

Wait time was interconnected with the type of teacher elicitation for knowledge and comprehension questions, supporting research that associates wait time and a question's cognitive level (Boeck and Hillenmeyer, 1973; Riley, 1986; Swift and Gooding, 1983; White and Lightbown, 1984). Rowe (1974a,b; 1976) did not analyze wait time relative to teacher elicitation level, and while Tobin (1986) coded for different questions types, he did not examine changes in wait time that may have arisen from these differences. Instead, he observes that the number of questions that "solicit student understanding" rather than "recall [of] facts" increases in extended wait time contexts (Tobin, 1986, p. 198). Unlike previous research, in this study, this relationship does not occur in application level questions. The incongruous results may reflect the low number of application questions in the sample, as one or two disproportionately low wait times could have skewed the data. Additionally, the two most proficient students responded to the few 
application questions, and the highest cognitive level classifications (i.e., analysis and synthesis) were not found in the data. Holistically, we can correlate extended wait time with longer student responses, as wait time is interrelated with question type. Teachers wanting to encourage longer, self-selected student speech in their classrooms should note this relationship. It is also important to note that lower cognitive level questions serve multivariate purposes in the classroom, and should not be avoided simply because they entail shorter responses. However, the graphs in Section 3 show that it is easy for discourse to move into an extended low-response state where there are low-level questions and that it may be difficult to break this pattern once entered. This phenomenon may be due to teachers having more control over speech in this environment and students being more comfortable responding to lower-level questions. In short, while instructors can consciously lengthen wait time, they cannot directly control how students respond to questions. They can, however, alter the types of questions they ask as an indirect means of manipulating wait time.

\subsection{Student-initiated speech}

The number of student-initiated questions was low in all observations, including those with longer than average wait time, conflicting with findings that student-initiated questions increase with extended wait time (Honea, 1982; Rowe's 1974a,b). However, these studies involved manipulation of wait time, whereas this research was conducted using a natural enquiry method. Additionally, this study only observes whole class activity, and previous L2 classroom research shows more student-initiated questions in small-group, rather than whole-class interactions (see Zhang, 2011). In observations with more student-initiated turns, many were one or two-word utterances and/or interruptions. Accordingly, if decreased student interruptions and 
longer student responses are characteristic of desirable classroom discourse, the student-initiated turns in our sample do not fit this definition. The student-initiated turns found in Honea's (1982) study include longer and more complex utterances indicative of high-quality discourse. This discrepancy highlights the importance of context, as solely looking at the high number of student-led turns in the six observations may have indicated a communicative classroom discourse environment, which was not the case here.

In this classroom, the turn-taking structure favored IRF, a discourse pattern prominent in classrooms across education levels, locations, and lesson content (van Lier, 1996). IRF discourse structures found herein were, in part, enabled by elicitations and codependent wait time, which helped to move the system toward the IRF attractor state. Ingram and Elliott (2014) find that the very concept of wait time depends on a formal turn-taking classroom discourse structure, i.e., IRF-focused discourse. They (2014, p. 10) note that in student-driven discourse, such as debates and student discussions "the rules of turn taking alter to those that govern ordinary conversation [and] the gaps between turns become minimized," and the need for wait time disappears. However, while student-driven discourse is desirable in many communicative classrooms, at times it "may...reduce the tendency to supply extended answers or explanations... [and] also create a bias in the participation... towards certain students who are happy to self-select," which disadvantages more reticent students (Ingram and Elliott, 2014, p. 10). The following extract shows an example of this bias in this study:

Extract 8: Observation 1

140 Ibrahim

141 Teacher

142 Students 143 Teacher 144 Amir
Windscreen Windscreen yeah [xxx] Which is?

At the top
R $\mathrm{F}$ $\mathrm{R}$ I $\mathrm{R}$ 
145 Ibrahim

146 Amir

147 Teacher

148 Ibrahim

149 Amir

150 Ibrahim

151

152 Ibrahim
Which is near the front of

At the top

It's the piece of glass

Yeah yeah yeah

Really?

Yeah. You don't know?

[Amir laughs]

Windscreen yeah ha ha
$\mathrm{R}$

$\mathrm{R}$

$\mathrm{F}$

$\mathrm{R}$

I

$\mathrm{R} / \mathrm{I}$

$\mathrm{R}$

While student-driven speech is generally considered a positive classroom discourse feature, these student utterances are short, and the teacher must eventually step in to provide an explanation. The students here are also the most proficient students in the class, making it easier for them to interpret the silence as an invitation to self-select when the teacher does not preselect a student. Although wait time helps enable the IRF structure, implementing longer wait time can be useful for teachers who want to encourage longer student utterances and "shift the classroom interaction system out of the minimal response [state] and into a different trajectory" (Larsen-Freeman and Cameron, 2008, p. 215). Wait time can help the teacher manage classroom discourse in a way which favors the IRF sequence, "help[ing] reduce the complexity of the system by narrowing down choices for participants" (Cameron and Larsen-Freeman 2007, p. 236). Short wait time equally helps enable this "reduced complexity," but often produces "talk with fairly short turns" preventing both student-driven discourse and extended student speech (Larsen-Freeman and Cameron, 2008, p. 181). Thus, prevalence of teacher-centric discourse structures does not always imply a teacher-focused classroom environment. Rather than a positive/negative binary, IRF should be viewed as a structure in which many different speech acts can be achieved. 
Filled pauses were only tangentially related to wait time. Teacher filled pauses seemed to operate pragmatically to control conversational turns, a function of filled pauses used more frequently by native speakers than nonnative speakers (Amiridze, Davis and Maclagan, 2010; Swerts, 1998). The teacher's filled pauses were often found in sequences with lots of teacher speech and short wait time, suggesting a more teacher-controlled environment. To date, there have been no studies on how wait time affects other pauses in the classroom, although Honea (1982) does note that longer wait time can lead to longer pauses in student-student conversation.

\subsection{The complexity of wait time}

At times, our results align with previous research, but often do not due to important contextual and methodological differences. This research represents the only current wait time study on L2 university students, and while Shrum's studies $(1984 ; 1985)$ come closest contextually, her research concerns younger students than does this study. The differences in L1 and L2 student speech could account for many of the differing results, especially those involving student-initiated questions, which were so few that little analysis could be conducted. Forming questions is also exceedingly more difficult for nonnative speakers than for L1 students. Because L2 classroom discourse is vastly different from L1 student discourse, this aspect must be accounted for when analyzing similar or discrepant results.

This research is unique in its complexity theory methodology, which has not yet been used in wait time research. Paired with conversation analysis, our approach reveals wait time's multivariate functions in the interpretive acts of the teacher and student, as just one of many factors within the 'local and sequential phenomenon,' at play (Markee, 2015, p. 10). The main limitation of previous studies stems from their inability to allow for the complexities of the 
classroom as a social ecosystem, as there are numerous dynamic factors which affect student achievement, such as fluctuating levels of motivation, language anxiety, topic interest, and so on (see Dörnyei, MacIntyre and Henry, 2015). Tobin (1987, p. 91) articulates this issue best in his review of wait time literature, which concludes "wait time...[is] a necessary but insufficient condition for higher cognitive level achievement" in classrooms which promote high cognitive level thinking. Educational research framed by complexity theory does not require uncompromising positions found in previous wait time research and in fact encourages a focus on the dynamic interaction of causal variables (de Bot et al., 2007).

The complexity perspective of this study allows for a wide analysis of wait time and classroom discourse. Wait time appears to correlate to the length of student discourse, most likely due to its codependence on other variables in the system, e.g., question type and other pauses. Complexity-informed research in language classrooms is crucial for revisiting previous research of seemingly static systems and looking for patterns that were previously unnoticed or under researched (Cameron and Larsen-Freeman, 2007).

\section{CONCLUSION}

This study revisits the concept wait time and its effects on classroom discourse, a topic which has been thoroughly neglected within applied linguistics research in recent years. This deficit of wait time research has less to do with the topic itself and more with the methodological approaches used by previous wait time researchers. While past researchers did recognize the effects that contextual classroom information can have, it was not a focal point for their quantitative research. Complexity-orientated research is inherently context-bound (King, 2015; Ushioda, 2015), and so a research design which consists of a descriptive analysis of a single 
classroom environment is perfectly legitimate as it allows for a focus on individual variation and dynamic change. The classroom discourse system observed in this study is wholly unique, as its component actors, initial conditions, feedback and other variables do not exist in any other context. Consequently, the movement and patterns found in a system created by such variables are equally distinct, so future researchers should be wary of generalizing these results across populations.

Future wait time research should compare the effects of both teacher and student wait time, as only teacher wait time was observed in the current study. Another area in need of consideration is how social and cultural variables can affect patterns of wait time in classroom interaction. As all but one of the students in our study spoke Arabic as their mother tongue, we suggest performing future research in multilingual classrooms. We found no visible relationship between the number of student-initiated turns/student questions and wait time length. Future studies could focus on these two variables however, as there may exist a pattern more intricate than was observable here, rather than simply reacting chaotically. Additionally, as this research did not analyze student speech for utterance complexity, it would be useful for future wait time studies to measure student speech complexity relative to wait time length.

This study is the first to look at wait time through a DST perspective, and the most important finding is the intricate nature of wait time's interactions with certain aspects of classroom discourse and how these interactions produce non-linear and feedback sensitive reactions in the classroom discourse system. The complexity framework allows for thorough analysis of the previously determined variables, as well as provides new insight into wait time's effects on turn-taking structures in classroom environments. Specifically, with the group we observed, it was found that: 1) Wait time played an intricate role in determining classroom 
discourse patterns and heavily favored an IRF turn-taking sequence; 2) Student-initiated discourse was low in all observations and favored higher proficiency students; 3) The length of individual student-initiated turns appears to have been more important than the overall number of student-initiated turns in determining the quality of classroom discourse and was not directly related to changes in wait time length; 4) Extended wait time (over 2 seconds in length) temporarily shifted discourse out of an IRF pattern and into a new, more student-driven phase. Practically, these findings can aid both second language teachers, and educators in general, in determining if extended wait time would be beneficial for their students. Wait time has varied effects on discourse, sometimes promoting longer, student-driven speech and at times, enabling a teacher-led discourse structure. Both types of discourse are useful in the classroom, thus teachers can use the patterns found here as indicative of the effects that wait time may have in their own classrooms and how they can manipulate it by means of the types of questions asked to help achieve a particular discourse environment. There remains no consensus on best practice in classrooms and other educational environments, regarding wait time. This is significant, as it means the best results research can achieve will elucidate patterns in educational ecosystems that highlight and account for the complexity of the classroom environment and of each individual actor and variable, as they themselves are also complex systems (Mercer, 2014, 2015). At the very least, it is hoped this study will help educators and educational researchers acknowledge the benefits that complexity-informed research can provide in discovering relationships between classroom aspects that may otherwise go unnoticed without a methodology that encourages context-driven differences. 


\section{ACKNOWLEDGEMENTS}

Jim King would like to acknowledge the Study Leave support provided to him by the University of Leicester's College of Social Sciences, Arts and Humanities.

\section{REFERENCES}

Amiridze, N., Davis, B. H., and Maclagan, M. (2010). Fillers, pauses and placeholders. Philadelphia: John Benjamins.

Bloom, B. S. (Ed.). (1956). Taxonomy of educational objectives; the classification of educational goals. New York: David McKay.

Boeck, M., and Hillenmeyer, G. (March 1973). Classroom interaction patterns during microteaching: Wait-time as an instructional variable. Paper presented at the Annual Meeting of the American Educational Research Association, New Orleans.

Cameron, L., and Larsen-Freeman, D. (2007). Complex systems and applied linguistics. International Journal of Applied Linguistics, 17(2), 226-240.

Csizér, K., and Magid, M. (Eds.). (2014) The impact of self-concept on second language learning. Bristol: Multilingual Matters.

de Bot, K., Lowie, W., and Verspoor, M. (2007). A dynamic systems theory approach to second language acquisition. Bilingualism: Language and Cognition, 10(1), 7-21.

Dörnyei, Z. (2007). Research methods in applied linguistics: Quantitative, qualitative, and mixed methodologies. Oxford: Oxford University Press.

Dörnyei, Z., MacIntyre, P. D., and Henry, A. (Eds.). (2015). Motivational dynamics in language learning. Bristol: Multilingual Matters. 
Duell, O., Lynch, D., Ellsworth, R., and Moore, C. (1992). Wait-time in college classes taken by education majors. Research in Higher Education, 33(4), 483-495.

Duell, O. (1994). Extended wait time and university student achievement. American Educational Research Journal, 31(2), 397-414.

Ellis, N.C., and Larsen-Freeman, D. (2006). Language emergence: Implications for applied linguistics - Introduction to the special issue. Applied Linguistics, 27(4), 558-589.

Ellis, N.C., and Larsen-Freeman, D. (Eds.). (2009). Language as a complex adaptive system. Oxford: Wiley-Blackwell.

Flowerdew, J., and Tauroza, S. (1995). The effect of discourse markers on second language lecture comprehension. Studies in Second Language Acquisition, 17(4), 435-458.

Gambrell, L. (1983). The occurrence of think-time during reading comprehension instruction. Journal of Educational Research, 77(2), 77.

Hale, C. (2011, July). Breaking with the IRF and EPA: Facilitating student initiated talk. Paper presented at the JALT2010 Conference, Tokyo, Japan. Retrieved from http://jaltpublications.org/proceedings/articles/1009-breaking-irf-and-epa-facilitating-studentinitiated-talk.

Harumi, S. (2011). Classroom silence: Voices from Japanese EFL learners. ELT Journal, 65(3), 260-269.

Honea, J. M. (1982). Wait-time as an instructional variable: An influence on teacher and student. Clearing House, 56(4), 167-170.

Horn, J. (2008). Human research and complexity theory. Educational Philosophy and Theory, 40(1), 130-143. 
Ingram, J., and Elliott, V. (2014). Turn taking and 'wait time' in classroom interactions. Journal of Pragmatics, 62, 1-12.

King, J. (2013). Silence in the second language classroom. Basingstoke: Palgrave Macmillan.

King, J. (Ed.) (2015). The dynamic interplay between context and the language learner. Basingstoke: Palgrave Macmillan.

Kirton, A., Hallam, S., Peffers, J., Robertson, P., and Gordon, S. (2007). Revolution, evolution or a Trojan horse? Piloting assessment for learning in some Scottish primary schools. British Educational Research Journal, 33(4), 605-627.

Larsen-Freeman, D. (1997). Chaos/complexity science and second language acquisition. Applied Linguistics, 18(2), 141-165.

Larsen-Freeman, D., and Cameron, L. (2008). Complex systems and applied linguistics. Oxford: Oxford University Press.

Long, M., and Sato, C.J. (1983). Classroom foreigner talk discourse: Forms and functions of teachers' questions. In H.W. Seliger and M.H. Long (Eds.). Classroom-oriented research on second language acquisition (pp. 268-285). Rowley, MA: Newbury House.

MacIntyre, P., and Legatto, J. (2011). A dynamic systems approach to willingness to communicate: Developing an idiodynamic method to capture rapidly changing affect. Applied Linguistics, 32(2), 149-171.

Markee, N. (Ed.) (2015). The handbook of classroom discourse and interaction. Oxford: WileyBlackwell.

Mercer, S. (2014). Reimagining the self as a network of relationships. In K. Csizér and M. Magid (Eds.) The impact of self-concept on second language learning (pp. 51-72).

Bristol: Multilingual Matters. 
Mercer, S. (2015). The contexts within me: L2 self as a complex dynamic system. In Author (2015).

Nakane, I. (2007). Silence in intercultural communication. Amsterdam: John Benjamins.

Riggenbach, H. (1991). Toward an understanding of fluency: A microanalysis of nonnative speaker conversations. Discourse Processes, 14(4), 423-441.

Riley, J. P. (1986). The effects of teachers' wait-time and knowledge comprehension questioning on science achievement. Journal of Research in Science Teaching, 23(4), 335-342.

Rossiter, M. J. (2009). Perceptions of L2 fluency by native and non-native speakers of English. Canadian Modern Language Review, 65(3), 395-412.

Rowe, M. B. (1969). Science, silence, and sanctions. Science and Children, 6(6), 11-13.

Rowe, M. B. (1974a). Reflections on wait-time: Some methodological questions. Journal of Research in Science Teaching, 11(3), 263-279.

Rowe, M. (1974b). Pausing phenomena: Influence on the quality of instruction. Journal of Psycholinguistic Research, 3(3), 203-224.

Rowe, M. B. (1986). Wait time: Slowing down may be a way of speeding up. Journal of Teacher Education, 37(1), 43-50.

Seedhouse, P. (2004). The interactional architecture of the language classroom: A conversation analysis perspective. Malden, MA: Blackwell.

Seedhouse, P. (2015). L2 classroom interaction as a complex adaptive system. In N. Markee (Ed.) The handbook of classroom discourse and interaction (pp. 373-389). Oxford: Wiley-Blackwell.

Seliger, H.W, and Long, M.H. (Eds.). (1983). Classroom-oriented research on second language acquisition. Rowley, MA: Newbury House. 
Shrum, J. L. (1984). Wait-time and student performance level in second language classrooms. Journal of Classroom Interaction, 20(1), 29-35.

Shrum, J. L. (1985). Wait-time and the use of target or native languages. Foreign Language Annals, 18(4), 305-314.

Sinclair, J. M., and Coulthard, M. (1975). Towards an analysis of discourse. Oxford: Oxford University Press.

Stahl, R.J. (1994). Using "think-time" and "wait-time" skillfully in the classroom. ERIC Digest (May 1994). Retrieved from ERIC database (ED370885).

Sun, Z. (2012). An empirical study on new teacher-student relationship and questioning strategies in ESL classroom. English Language Teaching, 5(7), 175-183.

Swerts, M. (1998). Filled pauses as markers of discourse structure. Journal of Pragmatics, 30(4), 485-496.

Swift, J. N., and Gooding, C. T. (1983). Interaction of wait time feedback and questioning instruction on middle school science teaching. Journal of Research in Science Teaching, 20(8), 721-730.

Thelen, E., and Smith, L. B. (1994). A dynamic systems approach to the development of cognition and action. Cambridge, MA: MIT Press.

Tincani, M., and Crozier, S. (2008). Comparing brief and extended wait-time during small group instruction for children with challenging behavior. Journal of Behavioral Education, 17(1), 79-92.

Tobin, K. (1986). Effects of teacher wait time on discourse characteristics in mathematics and language arts classes. American Educational Research Journal, 23(2), 191-200. 
Tobin, K. (1987). The role of wait time in higher cognitive level learning. Review of Educational Research, 57(1), 69-95.

Ushioda, E. (2015). Context and complex dynamic systems theory. In Z. Dörnyei, P. MacIntyre, and A. Henry (Eds.). Motivational dynamics in language learning (pp 47-54). Bristol: Multilingual Matters.

van Geert, P. and van Dijk, M. (2002) Focus on variability: New tools to study intra-individual variability in developmental data. Infant Behavior and Development, 25, 340-374.

van Lier, L. (1996). Interaction in the language curriculum: Awareness, autonomy, and authenticity. New York: Longman.

van Lier, L. (2004). The ecology and semiotics of language learning: A sociocultural perspective. Norwell, MA: Kluwer Academic.

Verspoor, M., Lowie, W., and van Dijk, M. (2008). Variability in second language development from a dynamic systems perspective. Modern Language Journal, 92(2), 214-231.

Verspoor, M., de Bot, K., and Lowie, W. (2011). Dynamic Approaches to Second Language Development: Methods and techniques. Amsterdam: John Benjamins.

Vogler, K. (2005). Improve your verbal questioning. Clearing House, 79(2), 98-103.

Waninge, F., Dörnyei, Z., and de Bot, K. (2014). Motivational dynamics in language learning: Change, stability, and context. Modern Language Journal, 98(3), 704-723.

Waring, H. (2009). Moving out of IRF: Initiation, Response, Feedback: A single case study. Language Learning, 59(4), 796-824.

Watanabe, M., Hirose, K., Den, Y., and Minematsu, N. (2008). Filled pauses as cues to the complexity of upcoming phrases for native and non-native listeners. Speech Communication, 50(2), 81-94. 
White, J., and Lightbown, P. (1984). Asking and answering in ESL classes. Canadian Modern Language Review, 40(2), 228-244.

Yashima,T., Ikeda, M., and Nakahira, S. (2015). Talk and silence in an EFL classroom: Interplay of learners and context. In Author (2015).

Zhang, H. (2011). Language anxiety in ESL classroom: Analysis of turn-taking patterns in ESL classroom discourse. IPEDR, 18, 29-33.

\section{TABLES}

Table 1

Mean correlation values for wait time and student response length $(\mathrm{N}=145)$

\begin{tabular}{cccc}
\hline$n$ & $r$ & $t$ & $\mathrm{R}^{2}$ \\
\hline 145 & .42 & 5.4 & .16
\end{tabular}

Note. $\mathrm{p}<.01$, with significance $(\alpha)$ at $<.01$

Table 2

Average Wait Time and Student Response Length- Knowledge Questions 


\begin{tabular}{l|ccc}
\multicolumn{1}{c}{ Elicitations } & Wait Time & $\begin{array}{c}\text { Student } \\
\text { Response }\end{array}$ \\
\hline Observation 1 & 19 & 1.3 & 1.0 \\
Observation 2 & 15 & 1.3 & .75 \\
Observation 3 & 10 & 1.4 & 1.2 \\
Observation 4 & 6 & .9 & .7 \\
Observation 5 & 10 & .7 & .7 \\
Observation 6 & 17 & 1.3 & 1.1
\end{tabular}

Note. Wait time and student response length averages in Tables 2, 3, and 4 are measured in seconds.

Table 3

Average Wait Time and Student Response Length- Comprehension Questions

\begin{tabular}{l|ccc}
\multicolumn{2}{c}{ Elicitations } & Wait Time & $\begin{array}{c}\text { Student } \\
\text { Response }\end{array}$ \\
\hline Observation 1 & 16 & 2.1 & 2.4 \\
Observation 2 & 7 & 1.4 & 3.4 \\
Observation 3 & 25 & 2.6 & 3.9 \\
Observation 4 & 13 & 1.4 & 2.5 \\
Observation 5 & 20 & 1.6 & 2.7 \\
Observation 6 & 19 & 2.2 & 1.5
\end{tabular}

Table 4

Average Wait Time and Student Response Length- Application Questions

\begin{tabular}{l|ccc}
\multicolumn{2}{c}{ Elicitations } & $\begin{array}{c}\text { Average } \\
\text { Wait Time }\end{array}$ & $\begin{array}{c}\text { Average Student } \\
\text { Response }\end{array}$ \\
\hline Observation 1 & 1 & .4 & 3.2 \\
Observation 2 & 9 & 2.3 & 4.4 \\
Observation 3 & 1 & .5 & 8.2 \\
Observation 4 & 4 & 1.1 & 1.5 \\
Observation 5 & 3 & 1.5 & 2.0 \\
Observation 6 & 0 & 0 & 0
\end{tabular}


